九州大学学術情報リポジトリ

Kyushu University Institutional Repository

\title{
A Method for Analyzing Local Climates by Using an Infrared Radiation Thermometer together with Topographic Factors
}

Mori, Makito

Labolatory of Agricultural Meteorology, Faculty of Agriculture, Kyushu University

Kobayashi, Tetsuo

Labolatory of Agricultural Meteorology, Faculty of Agriculture, Kyushu University

Takemasa, Takehiro

Faculty of Engineering, Department of Civil Engineering, Nagasaki University

Takeshita, Kazuhiro

Labolatory of Agricultural Meteorology, Faculty of Agriculture, Kyushu University

他

https://doi.org/10.5109/24086

出版情報：九州大学大学院農学研究院紀要. 39 (3/4)，pp.243-254，1995-03. Kyushu University バージョン：

権利関係: 


\title{
A Method for Analyzing Local Climates by Using an Infrared Radiation Thermometer together with Topographic Factors
}

\author{
Makito Mori, Tetsuo Kobayashi, Takehiro Takemasa*, \\ Kazuhiro Takeshita** and Kenji Wakimizu
}

\author{
Labolatory of Agricultural Meteorology, Faculty of Agriculture, \\ Kyushu University, Fukuoka 812-81, Japan \\ (Received December 15, 1994)
}

\begin{abstract}
Thermal IR images obtained with an IR radiation thermometer installed on the roof of a high building and topographic factors evaluated from the data set of altitude (Digital National Land Information, Japan) are used together in the present method of analyzing local climates, especially during a calm night. The radiative temperature of a particular evergreen canopy, which is read from the thermal IR image and will be called the "canopy temperature", is shown to be in good agreement with the air temperature around tree crowns making up the canopy if the effect of water vapor in the atmosphere is removed. The canopy temperature is deeply influenced by the surrounding terrain features as well, and its regression equation on the topographic factors is constructed with high significance. Consequently, using the regression equation, air temperature distribution in complex terrain, especially at hight, can be estimated, which is served for a study of thermal belts on hillsides.
\end{abstract}

\section{INTRODUCTION}

One of the difficulties in studying local climates arises from the difficulty in acquiring appropriate data. In general, the data from official weather stations are not enough to analyze local climate phenomena, because the spacing between the stations is too great to get the data that describe processes occurring at the micro-, meso $\gamma$ and $\mathrm{p}$-scale.

Recently, however, excellent systems which give us thermal IR images of various objects have become available. This paper describes a method of using the IR images obtained with an IR radiation thermometer installed on an elevated spot, e. g. on the roof of a high building for analyzing local climatic phenomena, especially at night. In complex terrain it is difficult to take simultaneous IR images of all the observation area, therefore terrain features also are used as auxiliary means.

\section{METHODOLOGY}

The thermal IR images of the observation area are obtained with an IR radiation thermometer installed on the top of a high building. The radiative temperatures of particular evergreen canopies are read from the images by putting an appropriate

\footnotetext{
* Faculty of Engineering, Department of Civil Engineering, Nagasaki University, Nagasaki 852, Japan.

** Present affiliation: Municipal office of Fukuoka, Fukuoka 810, Japan.
} 
value to the IR emissivity of the canopy, which will henceforth be called the "canopy temperature". The canopy temperature is used as a local climatic element.

It is difficult, however, to take simultaneous thermal IR images of all the observation area in complex terrain. Thus the regression equation of the canopy temperature on the factors depicting the terrain features around the canopy are used to obtain the simultaneous distribution of canopy temperature through all the area.

In the present study, an IR radiation thermometer called "Thermo Tracer 6T62" (NEC San-Ei, in the 8-13 $\mu \mathrm{m}$ waveband) is used to take thermal IR images, and some topographic factors expressing terrain features are defined and evaluated from the data set of altitudes (Digital National Land Information, Japan).

\section{OBSERVATION}

Observations were made on 5 calm nights for the period of July 1990 to June 1992 in the northern part of Dazaifu City, situated to the southeast of Fukuoka City. The measurement sites in the present study are shown in Fig. 1 and they will be referred to as A- to I-station, respectively. A-station is located on the roof of the Dazaifu City hall (25 $\mathrm{m}$ above the ground of $40 \mathrm{~m} \mathrm{ASL}$ ), where the "Thermo Tracer 6T62" was

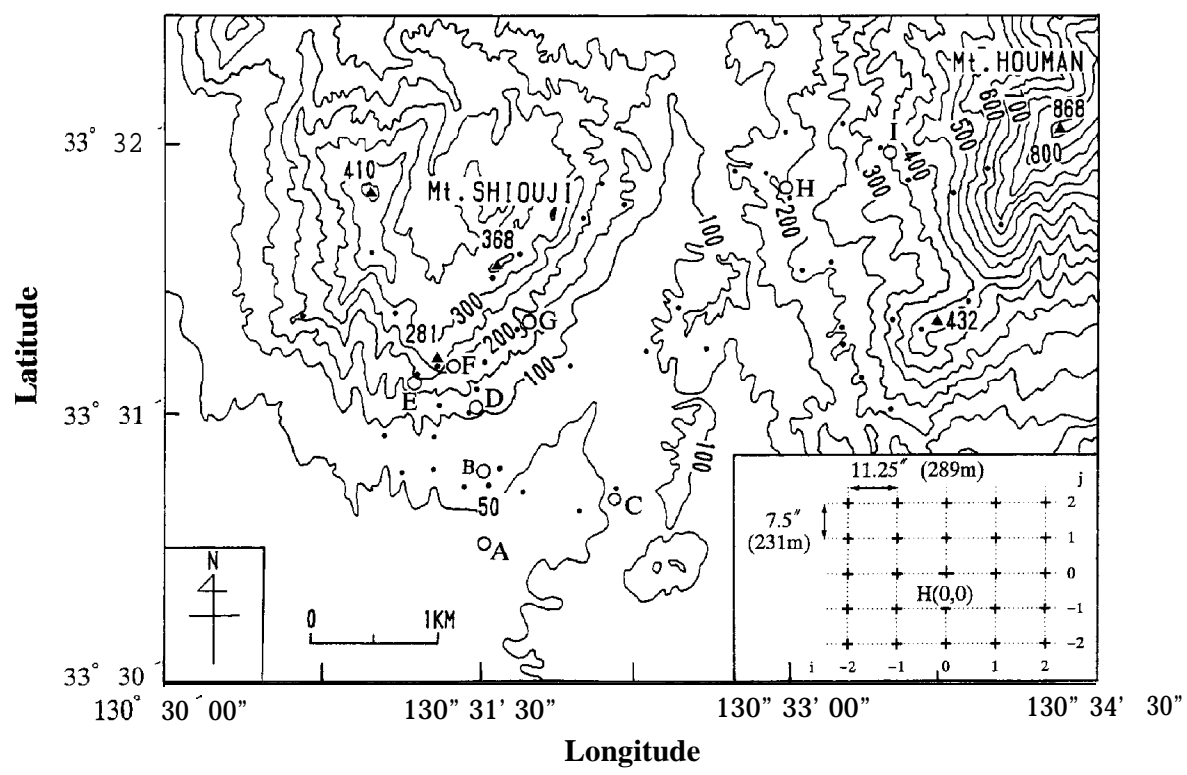

Fig. 1. Topographic map showing measurement sites in the northern part of Dazaifu, Fukuoka, Japan. The circles indicate the leaf and/or air temperature stations, Ato I-station. The dots distributed over the whole area show the locations of evergreen canopies where the "canopy temperature" measurements were made with an IR radiation thermometer installed at A-station. The mesh insetted in the figure represents the grid points of Digital National Land Information (Japan) deployed around a particular canopy (dot) and was used for the evaluation of topographic factors (Table 1). 
installed and the thermal IR images of the surrounding hills in several directions were obtained hourly. Essential meteorological elements such as wind speed and humidity were also observed at this station. At the other stations on hillsides, leaf and air temperatures along with the canopy temperature were measured.

The dots in Fig. 1 show the locations of evergreen canopies where the canopy temperature measurements were made from the thermal IR images obtained with the "Thermo Tracer 6T62". The number of these sites was 49 .

Leaf temperature measurements were made with thermocouple thermometers for surface temperature use. The sensor was attached to the center of back side of a leaf making up a canopy and being located outside of the crown at above $1.2 \mathrm{~m}$ height. Air temperatures were measured with thermistor thermometers with a simple shelter under the crown at a height above $1.2 \mathrm{~m}$ from ground.

\section{CANOPY TEMPERATURE}

\section{Emissivity}

Before the canopy temperature can be measured with an IR radiation thermometer, the IR emissivity $\varepsilon$ must be determined. However, determining the IR emissivities of leaves with fair accuracy needs a sophisticated device (Buettner and Kern, 1965 ;Idso et al., 1969). Since the purpose of the present study is not to measure the canopy temperature with precision but to utilize it as a measure of the air temperature, a rough estimate was made by comparing the leaf temperatures measured with a thermocouple thermometer (TNA-120, TASCO JAPAN) and those with a hand-held IR radiation thermometer (CT-30, COS, in the $6612 \mu \mathrm{m}$ waveband) assuming $\varepsilon$ to be one. The radiative surface temperature was measured with the IR radiation thermometer perpendicularly viewing the surface at a distance of a few centimeters.

An evergreen (Camellia sasanquaThunb.) which is widely and densely distributed in this area was used as the test material. The leaf has a width of about 2 to $3 \mathrm{~cm}$ and a length of about 5 to $6 \mathrm{~cm}$. Measurements were made nine times on calm nights in summer. The leaf temperatures were in the range of 27.6 to $30.7 \mathrm{C}$. The mean value of the emissivity was 0.995 , the standard deviation being 0.002 . Therefore, although this value of 0.995 may be too large for the emissivity because the radiation from surroundings was neglected in making the estimate (Idso et al., 1969), which causes an overestimation, the canopies of evergreens will be assumed as the blackbodies in this study for the sake of simplicity.

\section{Relationship between leaf and air temperature}

The difference between the temperatures of an isolated horizontal leaf and the air surrounding it during the night was studied by Leuning (1988). His results show that the difference is hardly greater than $4 \mathrm{C}$ when the wind blows at a speed above 0.2 $\mathrm{m} \mathrm{s}^{-1}$. The difference for the leaves making up a tree crown seems to be much less than for an isolated leaf (e. g., Balick and Wilson., 1980).

Both of the measurements of leaf and air temperature made in the present study were compared. Figure 2 shows the comparison between leaf and air temperatures taken on 5 nights (July 20-21 and Oct. 16-17, 1990; Sep. 5-6 and Nov. 29-30, 1991; June 


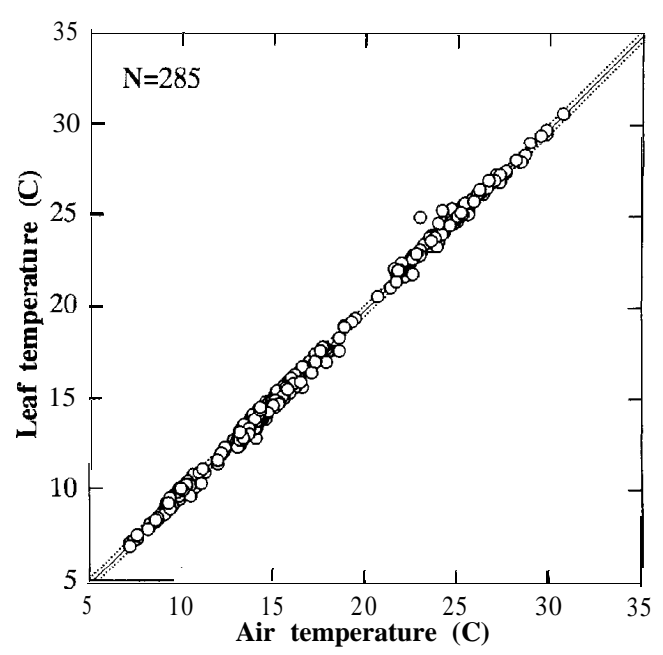

Fig. 2. Comparison between leaf and air temperatures taken on 5 calm nights, the sample size being 285 .

20-21, 1992). As is shown in the figure, leaf temperatures were on the average $0.2 \mathrm{C}$ lower than air temperatures (solid line), the standard deviation of the differences between them being $0.3 \mathrm{C}$ (dotted lines). Thus, the agreement between them was judged good enough for using the leaf temperature as a measure of the air temperature around the canopy to analyze local climates during the night.

\section{Relationship between canopy and leaf temperature}

The canopy temperature is a kind of average leaf temperature over the outside of tree crowns, which is remotely measured with an IR radiation thermometer, Thus the influence of matter such as water vapor on radiation cannot always be neglected. Figure $3 \mathrm{a}$ and $3 \mathrm{~b}$ illustrate the effect of water vapor in the atmosphere on the canopy temperature (dashed lines). When the average water vapor pressure $\overline{\mathrm{e}}$ at A-station for the whole night was $26.8 \mathrm{hPa}$ (Fig. 3a), the canopy temperature was much higher than the leaf temperature (solid lines). However, when the value of $\overline{\mathrm{e}}$ was $10.2 \mathrm{hPa}$ (Fig. 3b), there was only small discrepancy. These results imply that water vapor in the atmosphere has great influence on IR radiation in the $8-13 \mu \mathrm{m}$ waveband.

A simple stratified atmospheric equilibrium model was used to account for the effect of water vapor on IR radiative transfer. If local thermodynamic equilibrium and isotropic radiation were assumed to prevail, canopy temperature $\left(T_{c}\right)$ is related with leaf temperature $\left(T_{1}\right)$ by the following equation

$$
T_{c}^{4}=T_{1}^{4} \cdot \bar{\tau}-\int_{0}^{x} T^{4} \frac{\partial \bar{\tau}}{\partial x} d x
$$

where $\bar{\tau}$ is the average transmission and

$$
\bar{\tau}(x)=\exp \left(-10^{-5} e^{2} x / R T\right)
$$



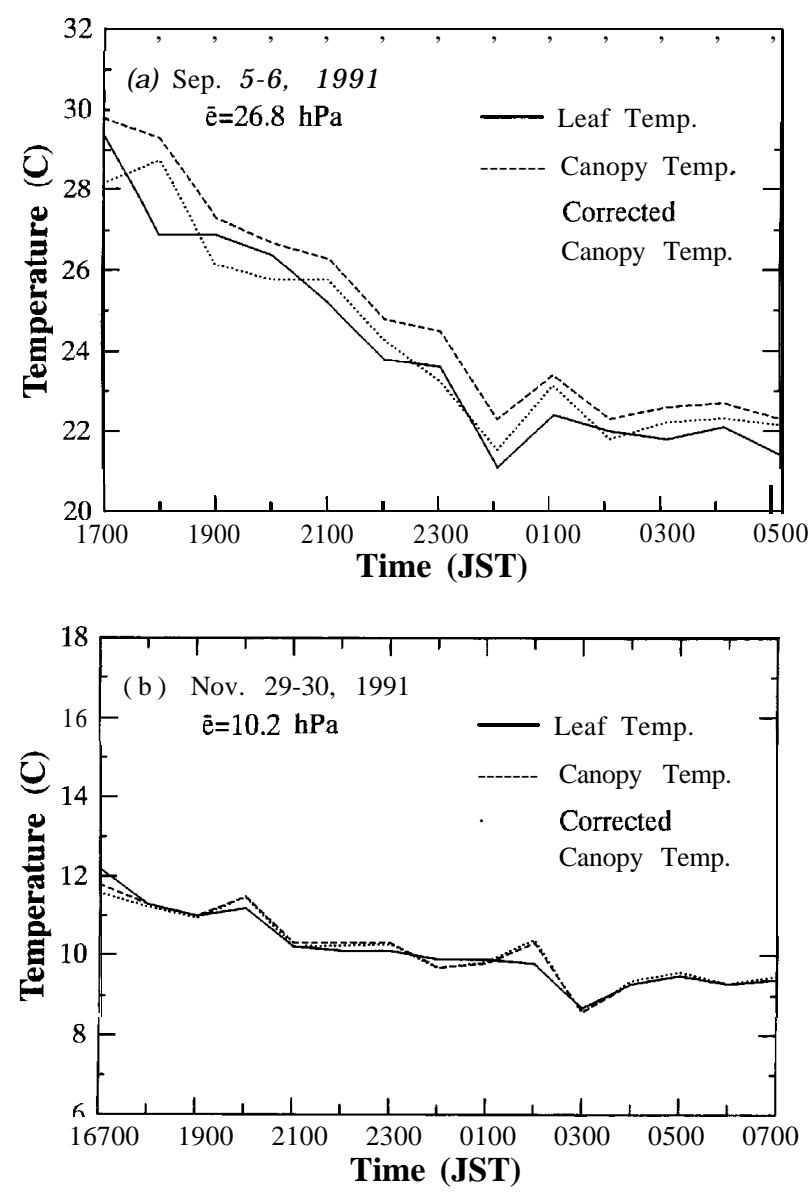

Fig. 3. Temporal variations in leaf, canopy and corrected canopy temperature at F-station (270 m ASL., $1.4 \mathrm{~km}$ away from A-station). The average water vapor pressures for the observation night at A-station were $26.8 \mathrm{hPa}$ (a) and $10.2 \mathrm{hPa}(\mathrm{b})$, respectively.

is used in the present study (Houghton, 1977) ; $T$ : air temperature, $e$ : water vapor pressure, $R$ : gas constant for water vapor, and $\mathrm{x}$ : distance along an IR ray path (in SI units).

Figure 4 depicts the variation of the average transmission $\tau$ with distance from A -station for the three nights (Oct. 16-17, 1990 ; Sep. 5-6 and Nov. 29-30, 1991). The transmission decreases exponentially with $\mathrm{x}$ and have the value less than 0.8 at $x=$ $4000 \mathrm{~m}$ when the vapor pressure larger than $10 \mathrm{hPa}$. Moreover, since $\tau$ is an exponential function of e to the minus second power, it becomes very small in moist conditions even at a short distance from A-station (Sep. 5-6, 1991). It is, therefore, necessary to remove the influence of water vapor in the air on the canopy temperature measured remotely with an IR radiation thermometer. 


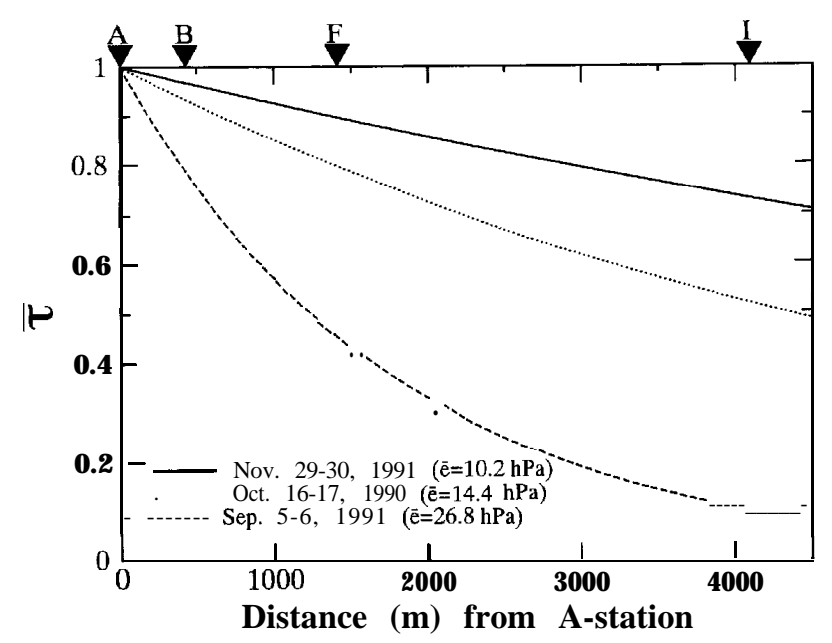

Fig. 4. The average transmission $\bar{\tau}$ as a function of the distance from A-station for the three nights.

Solving equation (1) numerically, $T_{1}$ was obtained from measurements of $T, e$ and $T_{c}$, which will be called "corrected canopy temperature" $\left(T_{C C}\right)$ for a while. The dotted lines in Fig. 3 show the corrected canopy temperatures obtained using water vapor pressures at A-station and air temperatures at A- and F-station. When the humidity is high (Fig. 3a), they are in fair agreement with the leaf temperatures. However, when the humidity is low (Fig. 3b), no sign of improvement is shown. From now on, the corrected canopy temperature $T_{C C}$ will be used in this study.

\section{Relationship between air and corrected canopy temperature}

Figure 5 shows the comparison between corrected canopy and air temperatures. Observations made on Oct. 16-17, 1990 ; Sep. 5-6 and Nov. 29-30, 1991, when humidity was measured hourly at A-station, were used in this analysis. The mean of the difference is $0.0 \mathrm{C}$ (solid line) and the standard deviation is about $0.5 \mathrm{C}$ (dotted lines). Consequently, the corrected canopy temperature can serve as a measure of the air temperature around the canopy during the night as well as does the leaf temperature.

\section{TOPOGRAPHIC FACTORS}

\section{Definition and evaluation}

Several topographic factors were used to express terrain features by numerical values. These factors can be evaluated from the data set of altitudes (Digital National Land Information, Japan) which gives us the altitudes at grid points with the resolution of about $289 \mathrm{~m} \times 230 \mathrm{~m}$ all over the study area (the inset in Fig. 1). The $\mathrm{H}$ $(0,0)$ in the figure is the altitude of the nearest grid point to a point where the canopy temperature is read from an IR image (dot). The main factors used in this study are the same as ones defined by Kobayashi et al. (1994) and summarized in Table 1. 


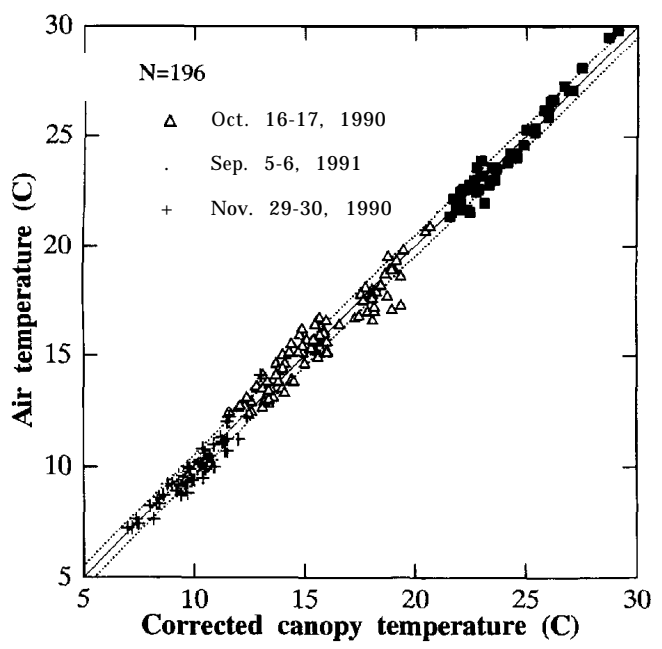

Fig. 5. Same as Fig. 2, but for corrected canopy and air temperatures for the three nights.

Table 1. Definition of topographic factors.

\begin{tabular}{|c|c|c|}
\hline \multicolumn{2}{|r|}{ Designation } & \multirow[t]{2}{*}{ Definition } \\
\hline$x_{1}$ & Altitude of a particular canopy (O) & \\
\hline$X_{2}$ & Degree of steep & $X_{2}=\operatorname{Max}[H(i, \mathrm{j})]-\operatorname{Min}[H(i, j)](i, \mathrm{j}=-2$ to 2$)$ \\
\hline$X_{3}$ & $\begin{array}{l}\text { Height difference from the mean } \\
\text { altitude over the observation area }\end{array}$ & $\begin{array}{l}X_{3}=\left|X_{1}-X_{m}\right|\left(X_{m}: \text { mean altitude over }\right. \\
\text { the observation area })\end{array}$ \\
\hline$X_{4}$ & Width of view & $\begin{array}{l}X_{4}=\text { Number of the grid points }[\leqq H(0,0)] \\
(\mathrm{i}, \mathrm{j}=-2 \text { to } 2 \text { ) }\end{array}$ \\
\hline$X_{5}$ & $\begin{array}{l}\text { Ratio of } X_{1} \text { to the altitude of the } \\
\text { hilltop }\end{array}$ & $\begin{array}{l}X_{5}=H(\bigcirc) / H_{t o p}\left(H_{t o p}: \text { altitude of the top of a }\right. \\
\text { hill around which the grid points (i, j= }-2 \text { to } 2) \\
\text { are deployed. }\end{array}$ \\
\hline
\end{tabular}

\section{Relationship between canopy temperature and topographic factors}

The relations of the canopy temperature to topographic factors for the two nights (Oct. 16-17, 1990 and Nov. 29-30, 1991) are shown in Table 2. For the former period, the water vapor pressure measurements at the nearest weather station (Fukuoka) were used to evaluate the average transmission because we did not measure humidity ourselves. The regression equations of the canopy temperature on the topographic factors were obtained on an hourly basis for each night. The significant topographic factors were selected by the F-test at a 0.01 level of significance and were normalized so that they have mean zero and variance one. Therefore the larger a partial regression coefficient shown in Table 2, the more closely the corresponding factor relates to the canopy temperature. The major topographic factors are the degree of steep $X_{2}$ and the height difference from the mean altitude over the observation area $X_{3}$. It can be seen that canopy temperature depends on the topographic undulation rather than the altitude $\left(X_{1}\right)$. 
Table 2. Relationships between the corrected canopy temperature $\boldsymbol{T}_{C C}$ and the topographic factors $X_{1}-X_{5}$ (Table 1) on Oct 16-17, 1990 and Nov. 29-30, 1991. The Numbers in the fourth to eighth columns show standard partial correlation coefficients (S. P. C. C.). The coefficients of multiple correlation $R$ are shown in the last column, where the sample size is 49 .

\begin{tabular}{|c|c|c|c|c|c|c|c|}
\hline \multirow{2}{*}{ Date } & \multirow{2}{*}{ Time (JST) } & \multicolumn{5}{|c|}{ S. P. c. c. } & \multirow{2}{*}{$R$} \\
\hline & & $X_{1}$ & $X_{2}$ & $X 3$ & $X_{4}$ & $X 5$ & \\
\hline \multirow[t]{11}{*}{1990} & 1800 & -0.70 & 0.34 & & & & 0.89 \\
\hline & 1900 & -0.34 & & & -0.47 & & 0.70 \\
\hline & 2000 & & & & & -0.78 & 0.78 \\
\hline & 2100 & -1.15 & 0.58 & & & & 0.72 \\
\hline & 2200 & & 0.70 & -0.59 & & -0.36 & 0.68 \\
\hline & 2300 & & 0.71 & -0.59 & & & 0.68 \\
\hline & 0000 & & 0.83 & -0.61 & & & 0.78 \\
\hline & 0100 & & 0.88 & -0.47 & & & 0.79 \\
\hline & 0200 & & 0.94 & -0.59 & & & 0.85 \\
\hline & 0300 & & 0.90 & -0.43 & & & 0.81 \\
\hline & 0500 & 0.54 & 0.64 & -0.60 & & & 0.91 \\
\hline & 0600 & & 0.84 & -0.47 & & & 0.76 \\
\hline \multirow[t]{7}{*}{$199111 / 29$} & 1700 & -0.63 & -0.18 & & & & 0.78 \\
\hline & 1800 & -0.69 & & & & & 0.69 \\
\hline & 1900 & & & -0.60 & & & 0.60 \\
\hline & 2000 & & & -0.67 & & & 0.67 \\
\hline & 2100 & -0.87 & 0.41 & & & & 0.58 \\
\hline & 2200 & & 0.29 & -0.48 & -0.17 & -0.52 & 0.75 \\
\hline & 2300 & & 0.25 & -0.58 & & & 0.52 \\
\hline \multirow[t]{7}{*}{$11 / 30$} & 0000 & -0.60 & 0.70 & -0.37 & & 0.54 & 0.65 \\
\hline & 0100 & 0.38 & 0.55 & -0.82 & & & 0.80 \\
\hline & 0200 & & 0.66 & -0.66 & & 0.37 & 0.83 \\
\hline & 0300 & -1.07 & 0.88 & -0.03 & & 0.61 & 0.58 \\
\hline & 0400 & 0.55 & 0.58 & -0.66 & -0.12 & & 0.85 \\
\hline & 0500 & 0.48 & 0.56 & -0.59 & & & 0.81 \\
\hline & 0600 & & 0.67 & -0.36 & -0.19 & 0.40 & 0.81 \\
\hline
\end{tabular}

Figure 6 shows an example of the degree of accuracy of the estimates made by using the regression equation. The measurements $T_{c c}$ are shown on the horizontal axis and the estimates $T_{e}$ are on the vertical. The regression equation seems to act as a filter which removes the effects other than the topographic ones, hence the estimated values of canopy temperature may be effective in analyzing topographic local climates, especially in the night with a clear sky.

\section{Canopy temperature distribution}

The canopy temperature ("corrected" will be omitted hereafter) distribution obtained from the thermal IR images taken with the IR radiation thermometer "Thermo Tracer 6T62" installed at A-station at 0500 JST of Oct. 17, 1990 is shown in Fig. $7 \mathrm{a}$, and the estimated distribution by using the following regression equation (3) (Table 2) is shown in Fig. $7 b$. 


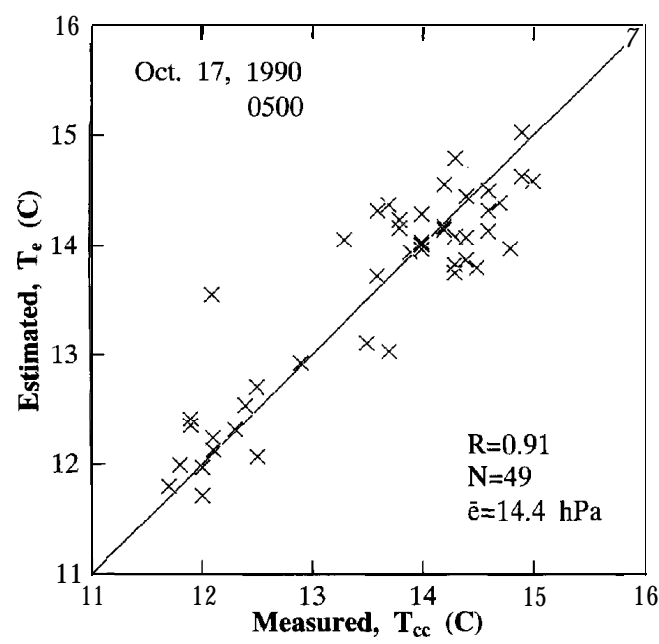

Fig. 6. A scatter diagram showing the degree of accuracy of the canopy temperature estimates $T_{e}$ made by a regression equation on the topographic factors.

$$
T_{e}=0.54 X_{1}+0.64 X_{2}-0.60 X_{3}
$$

This regression equation was obtained on the basis of the measured distribution shown in Fig. 7a and the topographic factors. The factors $X_{4}$ and $X_{5}$ were not judged to be significant at this time of day. It is a matter of course that we cannot get the IR image of the back of a hill, however we can estimate the canopy temperature distribution over the back area using the regression equation on the topographic factors.

In Fig. 7b we can see thermal belts (stippled areas) on both the hillsides of Mt. Houman and Mt. Shiouji. Although, in general, the location of thermal belt is regarded as the surface layer of a cold-air lake over the basin, the altitudes of warm zones are different from each other. This phenomenon is of interest and details on this was discussed in another report (Kobayashi et al., 1994).

Figure 8 shows the distribution of $T_{e}$ extended to the whole area of Dazaifu City. The altitude at which $12 \mathrm{C}$ isotherm runs is about $100 \mathrm{~m}$ ASL in the southern part of the city, while is about $50 \mathrm{~m}$ ASL in the center part, suggesting that in the lower regions below $100 \mathrm{~m}$ ASL the southern area is more cooler than the other area. Moreover, thermal belts are not found in the southern hilly region, where the slope is more gentle than the northern area and the topographic factors $X_{2}$ and $X_{3}$ are small. From these results we can get an idea that the occurrence of thermal belts on hillsides is closely related to how steep their slopes are. 


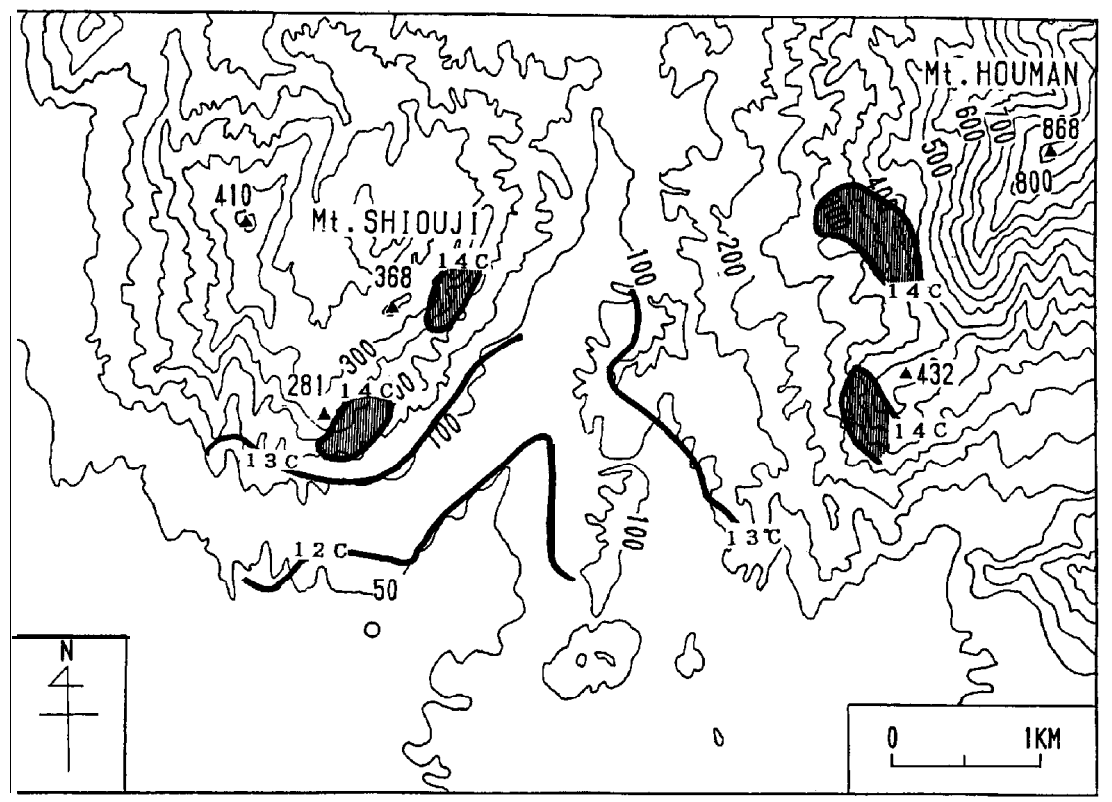

Fig. 7a. A canopy temperature distribution obtained with an IR radiation thermometer installed at A-station at 0500 JST of Oct. 17, 1990. The stippled areas show higher temperature regions.

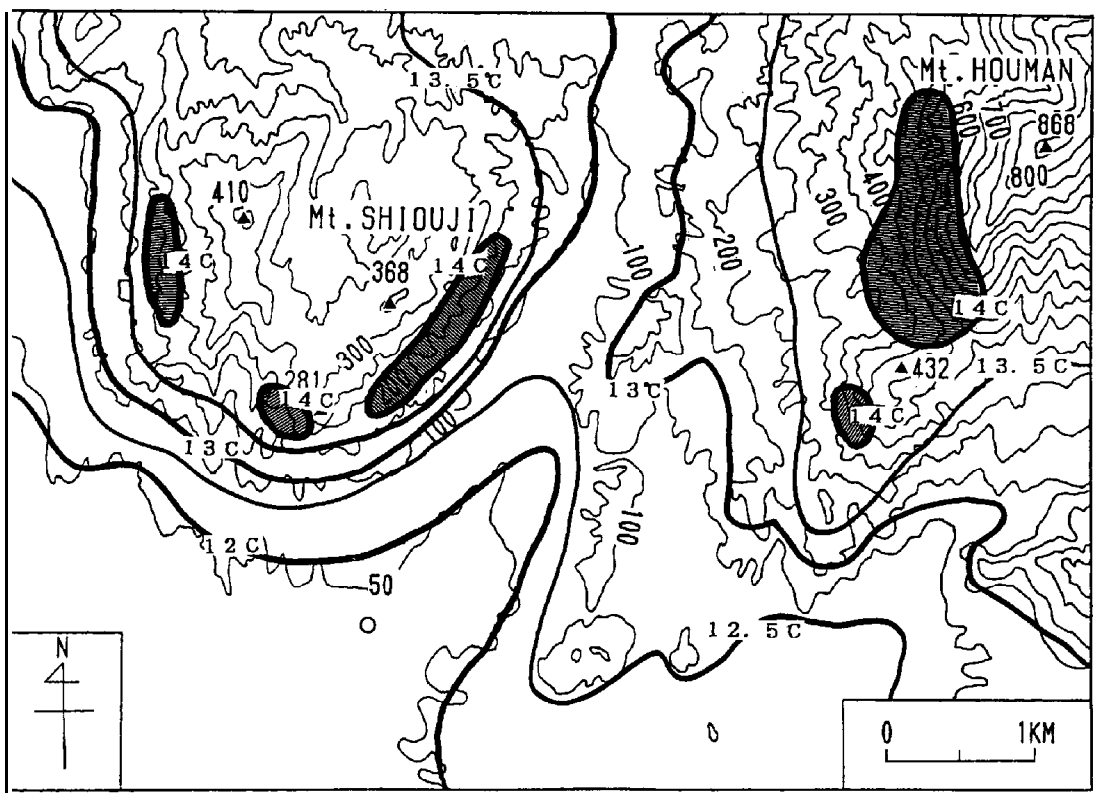

Fig. 7b. Same as Fig. 7a, but for the canopy temperature obtained using the regression equation based on the measurements shown in Fig. 7a. 


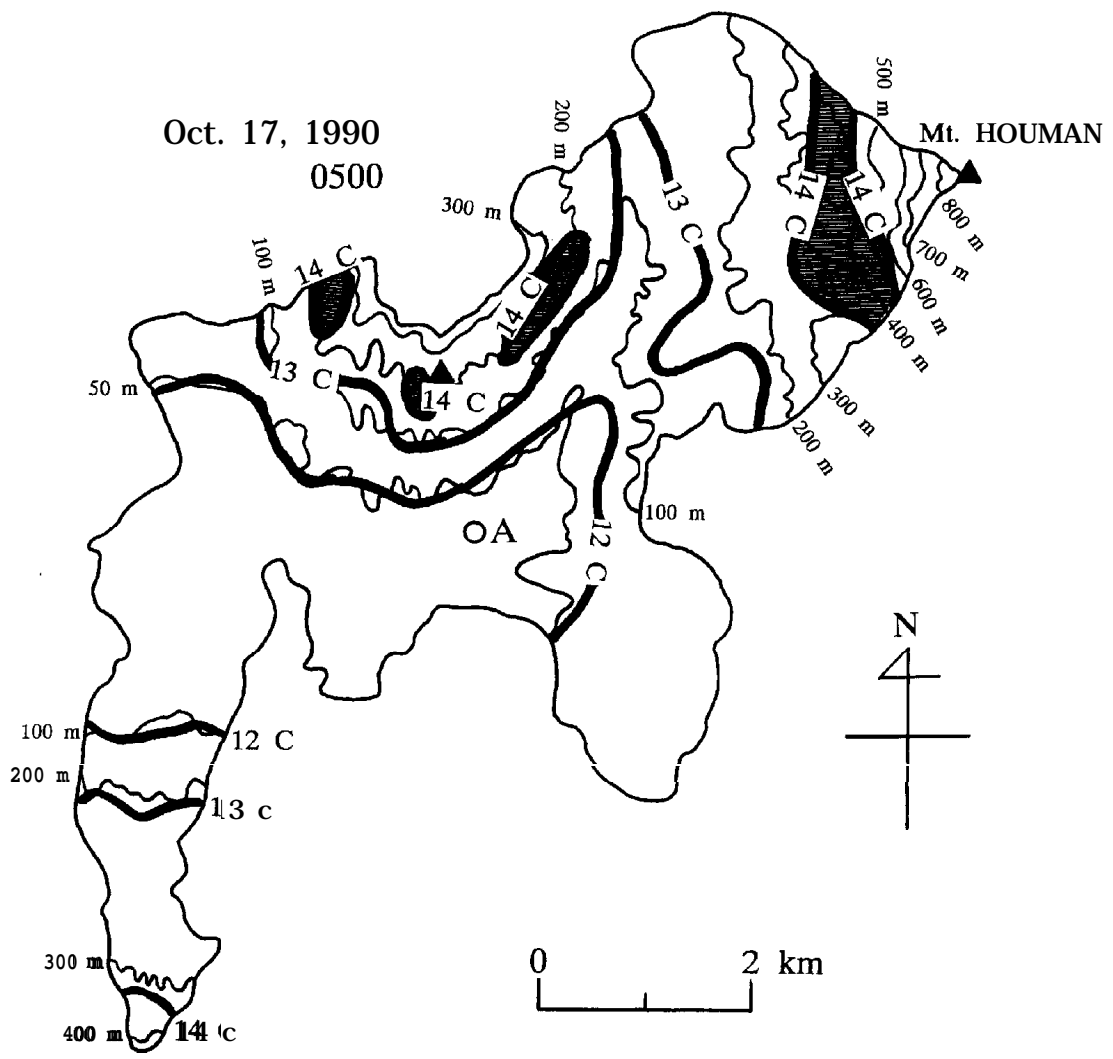

Fig. 8. Same as Fig. 7b, but for the whole area of Dazaifu City.

\section{CONCLUSIONS}

Some of the conclusions to be drawn from these results are as follows :

1) An IR radiation thermometer installed on the roof of a high building can measure the temperature of evergreen canopy in several kilometers neighborhood with an accuracy of $\pm 0.5 \mathrm{C}$ on calm nights if the effect of water vapor in the atmosphere is removed.

2) The canopy temperature is usually in good agreement with the air temperature around tree crowns making up the canopy from dusk to dawn.

3) The canopy temperature on calm nights is strongly influenced by the surrounding terrain features, so that we can make its regression equation on the topographic factors.

4) Consequently, the air temperature distribution in complex terrain on calm nights can be estimated by using the regression equation, which can be used effectively in studying local climates.

An IR radiation thermometer is surely effective in analyzing local climate phe- 
nomena on a calm and clear night. However, since the thermal IR image in the daytime is definitely affected by the solar radiation, the thermometer seems to be available for another and more restricted use at daytime.

\section{REFERENCES}

Balick, L. K. and S. K. Wilson 1980 Appearance of irregular tree canopies in nighttime high resolution thermal infrared imagery. Remote Sens. Environ., 10 : 299-305

Buettner, K. J. K. and C. D. Kern 1965 The determination of infrared emissivities of terrestrial surfaces. J. Geophys. Res., 70 : 1329-1337

Houghton, J. T. 1977 The physics of Atmosphere. Cambridge Univ. Press, London, pp. 31-45

Idso, S. B., R. D. Jackson, W. L. Ehrler and S. T. Mitchell 1969 A method for determination of infrared emittance of leaves. Ecology, $50: 899-902$

Kobayashi, T., M. Mori, K. Wakimizu and K. Takeshita 1994 An observational study of a thermal belt on hillsides. J. Meteor. Soc. Japan., $72: 387-399$

Leuning, R. 1988 Leaf temperatures during radiation frost. PART II. A steady state theory. Agr. Forest Meteor., 42 : 135-155 